\title{
Konik ışınlı bilgisayarlı tomografi istek nedenlerinin incelenmesi
}

\author{
Eda Didem Yalçın(0000-0003-3204-4609) ${ }^{\alpha}$, Aslıhan Artaş(0000-0001-6410-9126) ${ }^{\alpha}$
}

Selcuk Dent J, 2019; 6: 309-314 (Doi: 10.15311/selcukdentj.521096)

Başvuru Tarihi: 01 Şubat 2019 Yayına Kabul Tarihi: 06 Mayıs 2019

\section{öz \\ Konik ışınlı bilgisayarlı tomografi istek nedenlerinin incelenmesi}

Amaç: Bu çalışmanın amacı, bir diş hekimliği fakültesinde konik ışınlı bilgisayarlı tomografi (KIBT) istenme nedenlerinin ve bu isteklerin, yaş, cinsiyet ve bölümlere göre dağılımının retrospektif olarak incelenmesidir.

Gereç ve Yöntemler: Bu çalışmada, Gaziantep Üniversitesi Diş Hekimliği Fakültesi Ağız, Diş ve Çene Radyolojisi Anabilim Dalı'nda Mart 2017-Mayıs 2018 tarihleri arasında KIBT alınmış olan 1010 hastanın istek formları retrospektif olarak incelendi. KIBT istenme nedeni, istek yapan bölümler ve KIBT çekim alan boyutu değerlendirildi.

Bulgular: Toplam 1010 adet KIBT istek formu incelendi. En çok isteğin implant planlaması (\% 47,72) amacıyla olduğu belirlendi. Daha sonra sırasıyla, tümör ve kist benzeri patolojiler (\% 23,07), gömülü dişlerin lokalizasyonu ve komşu anatomik yapılarla ilişkisinin incelenmesi (\% 6,73) nedenleri ile istek yapıldığı saptandı.

Sonuç: Diş hekimliğinde birçok alanda kullanılan KIBT'ın en çok implant planlaması için istendiği tespit edildi. KIBT istek nedenlerinin incelenmesi; KIBT'ın kullanım alanlarının, sıklığının ve sınırılıklarının belirlenmesinde katkı sağlayacaktır.

\section{ANAHTAR KELIMELER}

Diş hekimliği, konik ışınlı bilgisayarlı tomografi, radyografi

Konvansiyonel yöntemler sadece iki boyutlu görüntü elde edilmesine olanak tanırken, son 20 yıl içinde diş hekimliğinde üç boyutlu görüntüleme yapılabilir hale gelmiştir. İntraoral ve ekstraoral iki boyutlu görüntüleme tekniklerinde meydana gelen magnifikasyon, distorsiyon, süperpozisyon gibi istenmeyen durumlardan dolayı üç boyutlu görüntüleme teknikleri geliştirilmeye çalışılmıştır. Böylece, üç boyutlu diş ve kemik morfolojisinin görüntüsel olarak iki boyuta indirgenmesinden kaynaklanan yetersiz/yanlış teşhislerin önüne geçmek mümkün olabilmektedir. ${ }^{1,2}$

Konik ışınlı bilgisayarlı tomografi (KIBT) yeni bir teknoloji olup ilk olarak 1982 'de anjiografi için geliştirilmiş daha sonraki dönemlerde maksillofasiyal

\author{
ABSTRACT \\ Examination of cone-beam computerized tomography \\ requests reasons
}

Background: The aim of this study is to retrospectively examine the reasons of cone-beam computed tomography (CBCT) request in a faculty of dentistry and the distribution of these requests according to age, gender and departments.

Methods: In this study, the request forms of 1010 patients who underwent CBCT between March 2017 and May 2018 in the Gaziantep University, Faculty of Dentistry, Department of Dentomaxillofacial Radiology were evaluated retrospectively. The reasons of the $\mathrm{CBCT}$ requests, the requesting departments and the field of view (FOV) were investigated.

Results: A total of 1010 СВCT request forms were investigated. It was determined that the most common request reason was implant planning (47.72\%). Followed by; tumor and cyst-like pathoses $(23.07 \%)$, localization of impacted teeth and their relation with adjacent anatomical structures $(6.73 \%)$ were detected, respectively.

Conclusion: CBCT, which is used in many fields in dentistry, was mostly requested for implant planning. Examination of the reasons for $\mathrm{CBCT}$ request will contribute to determine the indications, frequency and limitations of CBCT.

\section{KEYWORDS}

Dentistry, cone-beam computed tomography, radiography

görüntülemede kullanılmaya başlanmıştır. ${ }^{3}$ KIBT incelemelerinde diğer görüntüleme yöntemlerinde olduğu gibi olabilecek en kaliteli görüntü mümkün olan en az radyasyon miktarıyla elde edilmelidir. $\mathrm{Bu}$ da ALARA (As Low As Reasonably Achievable), doz optimizasyon prensibidir. Klinisyenler 'teşhis açısından kabul edilebilir' ve 'iyi' görüntü arasındaki riskleri göz önünde bulundurmalıdır. $\mathrm{Bu}$ durum ALARA'nın modifikasyonu ve yeni bir kavram olan ALADA (As Low As Diagnostically Acceptable)'yı ortaya çıkarmıştır. Tanısal olarak kabul edilebilir ve yorumlanabilir bir görüntü elde etmek için uygun görüntüleme alanı (Field of view-FOV), mAs ve kVp ayarları ve yüksek çözünürlük parametreleri seçilmelidir. ${ }^{4}$ En uygun doz oranı her zaman hesaplanamayacağı için bölgeler için belirlenmiş

${ }^{\alpha}$ Gaziantep Üniversitesi Diş Hekimliği Fakültesi Ağız, Diş ve Çene Radyolojisi AD, Gaziantep 
spesifik ölçülebilir doz miktarları arasından en optimum olanı seçilmelidir (SEDENTEXCT).$^{5}$

Her geçen gün kullanımı yaygınlaşan KIBT tekniğinin endikasyonları iyi bilinmelidir. ${ }^{6}$ KIBT diş hekimliğinde patolojilerin tanısında, tükürük bezi, maksiller sinüs ve temporomandibular eklem (TME) incelemesinde, endodontik patolojilerin teşhisinde, kanal yapılarının ve kök kırıklarının incelenmesinde, ortodontik anomalilerin teşhis ve tedavi planlamasında3, alveoler kemik defektleri ve furkasyon tutulumlarının saptanmasında, implant yapılacak alanların değerlendirilmesinde $\quad$ kullanılmaktadır. ${ }^{7}$ Ayrıca maksillofasiyal travma ve uyku apnesi vakalarında da kullanılabilmektedir 3

Literatürde KIBT çekimi için yapılan istek formlarının değerlendirildiği çalışmalar sınırlı sayıdadır. Warhekar ve ark. ${ }^{8}$, çalışmalarında 795 hastanın KIBT görüntüleri ile ilgili tesadüfi bulguları ve KIBT başvuru nedenlerini değerlendirmiş ve en sık olarak implant için kurum dışı özel sektörde çalışan oral cerrahların KIBT isteği yaptığını bildirmişlerdir.

Ülkemizde bu konuda yapılmış çalışmalar incelendiğinde, Ertaş ve Kalabalık ${ }^{9}$ tarafından yapılan araştırmada KIBT çekilmiş olan toplam 470 hastanın bilgileri değerlendirilmiş ve iki boyutlu radyografilerin sınırlı kaldığı pek çok vakada KIBT'ın vazgeçilmez bir teşhis aracı olduğu belirtilmiştir. Akarslan ve Peker 'in ${ }^{10}$ çalışmasında ise KIBT elde edilmesi için başvuran hastalara ait 1087 adet KIBT istek formu incelenmiş ve en çok isteğin implant planlaması amacıyla olduğu tespit edilmiştir. Gaziantep ve çevresinde bu alanda yapılan bir çalışmaya rastlanılmamıştır. Bu nedenle bu çalışmanın amacı, Gaziantep Üniversitesi Diş Hekimliği Fakültesi Ağız, Diş ve Çene Radyolojisi Anabilim Dalı'nda (ADÇR) konik ışınlı bilgisayarlı tomografi (KIBT) çekimi yapılmış olan hastalardan KIBT istenme nedenlerinin ve bu isteklerin, yaş, cinsiyet ve bölümlere göre dağılımının retrospektif olarak incelenmesidir.

\section{GEREÇ VE YÖNTEM}

Çalışmaya başlamadan önce Gaziantep Üniversitesi Etik Kurulu'ndan onay alındı (Karar No: 2018/111). Gaziantep Üniversitesi Diş Hekimliği Fakültesi ADÇR Anabilim Dalı'na Mart 2017-Mayıs 2018 tarihleri arasında başvuran hastalar arasından KIBT alınan 1010 (462 erkek, 548 kadın) hastanın KIBT istek formları retrospektif olarak incelendi. Fakültemizdeki bölümlerden ve ayrıca Gaziantep ili ve çevresinden KIBT çekimi için yönlendirilen bütün hastaların görüntülemeleri tek bir KIBT cihazından (Planmeca Promax 3D; Planmcea, Helsinki, Finland) yapıldı. Görüntüleme alanlarının 16x16, 16x9, 16x5, 7x7 cm FOV'da olduğu belirlendi. Tek diş KIBT istendiğinde ise cihazın limitasyonundan dolayı 4x5 cm FOV'da yarım çene görüntülendi. İstek formlarında istek yapanlardan; hastaya ait demografik bilgiler, klinik bilgi, klinik ön tanı, çekim istenilen bölge (mandibula, maksilla, üst yüz, paranazal sinüsler, TME, tüm yüz) ve istek yapılan bölüm ve doktora ait bilgiler istenilmiş olup, eksik doldurulan istek formları çalışma dışı bırakılmıştır. Kurum dışından KIBT çekimi için yönlendirilen hastaların KIBT istek formları Anabilim Dalımız tarafından dolduruldu. Çalışmaya dahil edilen formlardan elde edilen veriler doğrultusunda; hastaların cinsiyeti, yaşı, KIBT istenme nedeni, istek yapan birim ve bölümler ve KIBT çekim alanı kaydedildi. Elde edilen veriler tanımlayıcı istatistik yöntemleri kullanılarak analiz edildi.

\section{BULGULAR}

Bu çalışmada, yaşları 5 ile 85 arasında değişen (ortalama 38,31 \pm 18,53), 462 erkek ve 548 kadın toplam 1010 hastanın KIBT bulguları değerlendirildi. Yirmi üç farklı KIBT istenme nedeni olduğu saptandı. En çok istek nedeninin implant planlaması (\% 47,72) olduğu belirlendi. Bunu sırasıyla; kemik içi lezyonlar (\% 23,07), gömülü dişler (\% $6,73)$ ve ortodontik amaçlı $(\% 3,76)$ olarak yapılan istekler izlemişti (Tablo 1, Tablo 2). Implant planlamasında en sık olarak mandibula ve maksillanın birlikte görüntülenmesi için istek yapıldığı saptandı (Tablo 3). Kemik içi lezyonlar için yapılan istek formları incelendiğinde, en sık olarak mandibulanın görüntülendiği tespit edildi (Tablo 4). Gömülü dişlerin incelenmesinde ise en çok maksillanın görüntülenmesi için KIBT istenildiği belirlendi (Tablo 5). Gömülü dişlerin yer tespiti ve süpernümerer diş incelemesi ile ortodontik amaçlı KIBT istek nedenleri birbirinden farklı olup Ortodonti bölümünden ayrıca gömülü dişlerin yer tespiti ve süpernümerer diş incelemesi için KIBT istekleri yapılmıştır.

Cinsiyete göre istek nedenleri değerlendirildiğinde; hem kadın (\% 49,1) hem de erkek (\% 46,1) hastaya ait formlarda en çok yapılan isteğin implant planlaması amacıyla olduğu saptandı. Çocuk hastalarda yapılan KIBT isteklerinin ise en çok kemik içi lezyonlar (\% 31,03), ortodontik amaçlı (\% 16,6) ve gömülü dişlerin değerlendirilmesi $(\%$ 15,5) amacıyla olduğu saptandı.

Çekilen tüm KIBT'ların istek yapan bölümlere göre dağılımı Tablo 6'da, bölümler tarafından yapılan KIBT isteklerinin yaş ortalaması ve cinsiyete göre dağılımı Tablo 7'de yer almaktadır. En sık Ağız, Diş ve Çene Cerrahisi Anabilim Dalı tarafından istek yapıldığı ve istek nedeninin en çok implant yapılacak bölgenin değerlendirilmesi olduğu bulundu. Bunu sırasıyla kemik içi kist ve tümör benzeri lezyonlar, gömülü dişlerin lokalizasyonu ve gömülü dişlerin komşu dişlere ve anatomik yapılara olan yakınlığının incelenmesi için yapılan istekler izlemekteydi. KIBT incelemesi amacıyla istek yapan bölümler arasında ikinci sırada Ağız, Diş ve Çene Radyolojisi Anabilim Dalı, üçüncü sırada ise Periodontoloji Anabilim Dalı bulunmaktaydı. Bu bölümler tarafından yapılan KIBT istekleri incelendiğinde, en çok implant cerrahisi öncesi değerlendirme için istek yapıldığı belirlendi. Ayrıca bu bölümleri sırasıyla Ortodonti, Endodonti, Çocuk Diş Hekimliği Anabilim Dallarının izlediği gözlendi. 
Tablo 1.

\begin{tabular}{|c|c|c|c|c|}
\hline KIBT İncelemesi İstek Nedenleri & $\begin{array}{l}\text { Kadın } \\
\text { (N) }\end{array}$ & $\begin{array}{l}\text { Erkek } \\
(\mathrm{N})\end{array}$ & $\begin{array}{l}\text { Toplam } \\
\text { (N) }\end{array}$ & $\begin{array}{l}\text { Yüzde } \\
(\%)\end{array}$ \\
\hline Alveolar Kemik Rezopsiyonun Değerlendirilmesi & 7 & 2 & 9 & 0,89 \\
\hline Apeksteki Yabancı Cisimlerin Değerlendirilmesi & 2 & 2 & 4 & 0,4 \\
\hline Bifosfanata Bağlı Osteonekroz (BRONJ) & 1 & 1 & 2 & 0,2 \\
\hline $\begin{array}{l}\text { Diş Kökleri-Mandibular Kanal lilişkisinin } \\
\text { Değerlendirilmesi }\end{array}$ & 12 & 10 & 22 & 2,18 \\
\hline Dudak- Damak Yarığı & 8 & 8 & 16 & 1,58 \\
\hline Eksternal Rezorpsiyon & 1 & 1 & 2 & 0,2 \\
\hline Fasiyal Ağrı & 2 & 2 & 4 & 0,4 \\
\hline $\begin{array}{l}\text { Gömülü Dişlerin (Mandibular 3. molar hariç) } \\
\text { Lokalizasyonu ve Anatomik Yapilarla ilişkisinin } \\
\text { Değerlendirilmesi }\end{array}$ & 48 & 20 & 68 & 6,73 \\
\hline Gömülü Diş Kökü & 1 & 3 & 4 & 0,4 \\
\hline İmplant Planlaması & 269 & 213 & 482 & 47,72 \\
\hline Kraniofasiyal Deformite & 1 & 0 & 1 & 0,1 \\
\hline Kemik İçi Lezyon & 118 & 115 & 233 & 23,07 \\
\hline Mandibular Parestezi & 0 & 1 & 1 & 0,1 \\
\hline Oroantral Fistül & 2 & 0 & 2 & 0,2 \\
\hline Ortodontik amaçlı & 24 & 14 & 38 & 3,76 \\
\hline Ortognatik Cerrahi & 4 & 2 & 6 & 0,59 \\
\hline Paranazal Sinüs Patolojileri & 9 & 15 & 24 & 2,38 \\
\hline Pre-operatif Sinüs Lifting & 3 & 3 & 6 & 0,59 \\
\hline Sialolit & 1 & 0 & 1 & 0,1 \\
\hline Süpernümerer Diş & 10 & 19 & 29 & 2,87 \\
\hline TME Patolojileri & 9 & 4 & 13 & 1,29 \\
\hline Travma & 13 & 22 & 35 & 3,46 \\
\hline Yumuşak Doku Şişlikleri & 3 & 5 & 8 & 0,79 \\
\hline Toplam & 548 & 462 & 1010 & 100 \\
\hline
\end{tabular}

\section{Tablo 2.}

KIBT incelemesi istek nedenlerinin endikasyonlarına göre dağılımı

\begin{tabular}{lcc|}
\hline KIBT İncelemesi İstek Nedenleri & Sayı (N) & Yüzde (\%) \\
\hline Diş Kökleri-Mandibular Kanal Ilişkisinin Değerlendirilmesi & 22 & 2,18 \\
\hline Dudak-Damak Yarı̆̆ı & 16 & 1,58 \\
\hline $\begin{array}{l}\text { Gömülü Dişlerin (Mandibular 3. molar hariç) Lokalizasyonu } \\
\text { ve Anatomik Yapılarla Ilişkisinin Değerlendirilmesi }\end{array}$ & 68 & 6,73 \\
\hline Implant Planlaması & 482 & 47,72 \\
\hline Kemik İçi Lezyon & 233 & 23,07 \\
\hline Ortodontik Amaçı & 38 & 3,76 \\
\hline Paranazal Sinüs Patolojileri & 24 & 2,38 \\
\hline Süpernümerer Diş & 29 & 2,87 \\
\hline TME Patolojileri & 13 & 1,29 \\
\hline Travma & 35 & 3,46 \\
\hline Diğer & 50 & 4,96 \\
\hline Toplam & 1010 & 100 \\
\hline
\end{tabular}

Tablo 3.

İmplant planlaması için istenen KIBT incelemesinin bölgesel dağılımı

\begin{tabular}{|lcc|}
$\begin{array}{l}\text { Implant } \\
\text { Planlaması } \\
\text { Yapılan Bölge }\end{array}$ & $\begin{array}{c}\text { Sayı } \\
\text { (N) }\end{array}$ & $\begin{array}{c}\text { Yüzde } \\
(\%)\end{array}$ \\
\hline Maksilla & 114 & 23,7 \\
\hline Mandibula & 127 & 26,3 \\
\hline Mandibula-Maksilla & 241 & 50 \\
\hline Toplam & 482 & 100 \\
\hline
\end{tabular}

Tablo 4.

Kemik içi lezyonların
değerlendirilmesi için istenen KIBT
incelemesinin bölgesel dağılımı

\begin{tabular}{|lcc|}
\hline $\begin{array}{l}\text { Kemik İçi } \\
\text { Lezyonun } \\
\text { Bulunduğu Bölge }\end{array}$ & $\begin{array}{c}\text { Sayı } \\
(\mathbf{N})\end{array}$ & $\begin{array}{c}\text { Yüzde } \\
(\%)\end{array}$ \\
\hline Maksilla & 91 & 39 \\
\hline Mandibula & 111 & 47,7 \\
\hline Mandibula-Maksilla & 28 & 12 \\
\hline Üst yüz & 3 & 1,3 \\
\hline Toplam & 233 & 100 \\
\hline
\end{tabular}

Tablo 5.

Gömülü dişlerin incelenmesi için istenen KIBT incelemesinin bölgesel dağılımı

\begin{tabular}{|lcc|}
\hline $\begin{array}{l}\text { Kemik İçi } \\
\text { Lezyonun } \\
\text { Bulunduğu Bölge }\end{array}$ & $\begin{array}{c}\text { Sayı } \\
\text { (N) }\end{array}$ & $\begin{array}{c}\text { Yüzde } \\
(\%)\end{array}$ \\
\hline Maksilla & 41 & 60,3 \\
\hline Mandibula & 16 & 23,5 \\
\hline Mandibula-Maksilla & 11 & 16,2 \\
\hline Toplam & 68 & 100 \\
\hline
\end{tabular}


Tablo 6.

Tüm KIBT incelemesi istek nedenlerinin istek yapan bölümlere göre dağılımı

\begin{tabular}{|c|c|c|c|c|c|c|c|c|}
\hline KIBT İncelemesi İstek Nedenleri & $\begin{array}{l}\text { Ağız, Diş } \\
\text { ve Çene } \\
\text { Cerrahisi }\end{array}$ & $\begin{array}{l}\text { Ağız, Diş } \\
\text { ve Çene } \\
\text { Radyolojisi }\end{array}$ & Endodonti & Ortodonti & $\begin{array}{l}\text { Çocuk } \\
\text { Diş } \\
\text { Hekimliği }\end{array}$ & Periodontoloji & Toplam & $\begin{array}{l}\text { Yüzde } \\
\text { (\%) }\end{array}$ \\
\hline $\begin{array}{l}\text { Diş Kökleri-Mandibular Kanal Ilişkisinin } \\
\text { Değerlendirilmesi }\end{array}$ & 13 & 9 & 0 & 0 & 0 & 0 & 22 & 2,18 \\
\hline Dudak- Damak Yarığı & 3 & 2 & 0 & 11 & 0 & 0 & 16 & 1,58 \\
\hline $\begin{array}{l}\text { Gömülü Dişlerin (Mandibular 3. molar } \\
\text { hariç) Lokalizasyonu ve Anatomik Yapılarla } \\
\text { ilişkisinin Değerlendirilmesi }\end{array}$ & 46 & 19 & 0 & 3 & 0 & 0 & 68 & 6,73 \\
\hline İmplant Planlaması & 180 & 201 & 0 & 0 & 0 & 101 & 482 & 47,72 \\
\hline Kemik içi Lezyon & 179 & 52 & 2 & 0 & 0 & 0 & 233 & 23,07 \\
\hline Ortodontik amaçlı & 1 & 9 & 0 & 27 & 1 & 0 & 38 & 3,76 \\
\hline Paranazal Sinüs Patolojileri & 19 & 4 & 0 & 0 & 0 & 1 & 24 & 2,38 \\
\hline Süpernümerer Diş & 26 & 2 & 0 & 1 & 0 & 0 & 29 & 2,87 \\
\hline TME Patolojileri & 12 & 1 & 0 & 0 & 0 & 0 & 13 & 1,29 \\
\hline Travma & 25 & 10 & 0 & 0 & 0 & 0 & 35 & 3,46 \\
\hline Diğer & 33 & 11 & 2 & 3 & 0 & 1 & 50 & 4,96 \\
\hline Toplam & 537 & 320 & 4 & 45 & 1 & 103 & 1010 & 100 \\
\hline
\end{tabular}

Tablo 7.

Bölümler tarafından yapılan KIBT isteklerinin cinsiyet ve yaş ortalamasına göre dağılımı

\begin{tabular}{|lccccc|}
\hline & $\begin{array}{c}\text { Kadın } \\
(\mathbf{N})\end{array}$ & $\begin{array}{c}\text { Erkek } \\
(\mathbf{N})\end{array}$ & $\begin{array}{c}\text { Toplam } \\
(\mathbf{N})\end{array}$ & $\begin{array}{c}\text { Yaş ortalaması } \\
\pm \text { SS }\end{array}$ & $\begin{array}{c}\text { Yüzde } \\
(\%)\end{array}$ \\
\hline Ağız, Diş ve Çene Cerrahisi & 277 & 260 & 537 & $35,22 \pm 18,23$ & 53,17 \\
\hline Ağız, Diş ve Çene Radyolojisi & 180 & 140 & 320 & $42,06 \pm 17,14$ & 31,68 \\
\hline Periodontoloji & 60 & 43 & 103 & $53,30 \pm 12,39$ & 10,2 \\
\hline Ortodonti & 27 & 18 & 45 & $15,78 \pm 6,77$ & 4,45 \\
\hline Endodonti & 3 & 1 & 4 & $28,50 \pm 11,09$ & 0,4 \\
\hline Çocuk Diş Hekimliği & 1 & 0 & 1 & 11 & 0,1 \\
\hline Toplam & 548 & 462 & 1010 & $38,31 \pm 18,53$ & 100 \\
\hline
\end{tabular}

\section{TARTIŞMA}

Çalışmamızda fakültemizdeki bölümlerden ve ayrıca Gaziantep ili ve çevresinden KIBT çekimi için yönlendirilen hastaların KIBT istek formlarına ait veriler incelenmiştir. En çok KIBT istek nedeni önceki çalışmalarda da implant olup, bu çalışmada isteklerin yarıdan biraz azını oluşturmakta iken, Warhekar ve ark. ${ }^{8}$ tarafından yapılan çalışmada bu oran \% 52,7, Akarslan ve Peker' in ${ }^{10}$ çalışmasında ise $\% 42,04$ olup çalışma sonuçlarımız diğerleriyle uyumludur.

Konik ışınlı bilgisayarlı tomografi günümüzde en sık implant cerrahisi öncesi kemik miktarının, yüksekliğinin, genişliğinin ve angulasyonunun değerlendirilmesi amacıyla kullanılmakta olup ilgili bölgenin kesitsel görüntüleri sayesinde başarılı implant operasyonları gerçekleştirilmektedir. ${ }^{11}$
$\mathrm{Bu}$ çalışmada yapılan tüm KIBT istekleri incelendiğinde; en sık Ağız, Diş ve Çene Cerrahisi Anabilim Dalı tarafından istek yapıldığı ve istek nedeninin en çok implant yapılacak bölgenin değerlendirilmesi olduğu bulundu. Bununla birlikte, implant planlaması amacıyla kurum dışından hastaların KIBT çekimi için fakültemize yönlendirilmesi sonucunda, implant planlaması için en fazla istek yapan bölümün $A D C ̧ R$ olduğu tespit edildi. $B u$ sonuç; özel klinikler, çeşitli hastaneler ve ağız ve diş sağlığı merkezlerinden implant planlaması amacıyla yönlendirilen KIBT isteklerinin toplam isteklerin önemli bir kısmını oluşturduğunu göstermektedir.

Sunulan çalışmada kemik içi lezyonlar istek nedenleri arasında \% 23,07 oran ile ikinci sırada yer almış olup bu oran diğer çalışmalardan biraz daha yüksek olsa da sonuç uyumludur. Kemik içi lezyonları değerlendirmek için en çok Ağız, Diş ve Çene Cerrahisi Anabilim Dalı tarafından istek yapıldığı belirlendi. Ağız ve diş sağlığı merkezlerinden bu bölüme sevkle gelen maksillofasiyal lezyonu bulunan hastaların bu sonucu oluşturduğu düşünülmektedir.

Gömülü dişlerin lokalizasyonu ve mandibular kanal ve maksiler sinüs gibi çevre anatomik yapılarla ilişkileri, KIBT ile 
incelenebilmektedir. ${ }^{3} \mathrm{Bu}$ çalışmada gömülü dişlerin lokalizasyonu ve anatomik yapılarla ilişkisinin değerlendirilmesi için yapılan KIBT istekleri, \% 6,73 oranı ile üçüncü sırada saptandı. Bununla birlikte Ertaş ve Kalabalık9 tarafından yapılan araştırmada en çok isteğin $(\% \quad 32,13)$ gömülü dişlerin değerlendirilmesi amacıyla yapıldığı gözlenmiştir. Bu farklılığın bölgesel nedenli olabileceği düşünülebilir.

Travma hastalarında uygun radyografik tetkikin seçimi, doğru teşhis ve tedavi planlaması için oldukça önemlidir. ${ }^{12}$ Mandibula fraktürlerinde; panoramik radyograflarda süperpozisyon, magnifikasyon, distorsiyonların bulunması ve mandibuladaki minimal deplasmanlı veya oblik yöndeki fraktürlerin net olarak izlenememesinden dolayı KIBT görüntülerinin daha doğru bilgi verdiği saptanmıştır. ${ }^{13}$ Çalışmamızda tüm isteklerin \% 3,46'sında, Akarslan ve Peker'in ${ }^{10}$ araştırmasında ise \% 2,94 oranında travma nedeniyle KIBT isteğinin yapıldığı ve benzer sonuçların elde edildiği tespit edilmiştir.

Paranazal sinüslere ait KIBT bulguları; KIBT'ın esas istenme amacı farklı nedenler olsa da, sinüslerin görüntüleme alanına girmesi sebebiyle KIBT üzerinde ikincil olarak değerlendirilebilir. ${ }^{14}$ Çalışmamızda paranazal sinüs patolojilerini değerlendirmek amacıyla yapılmış KIBT istekleri, tüm isteklerin \% 2,38'ini oluşturmaktadır. Warhekar ve ark.'nın ${ }^{8}$ ise bu amaç için yapılan KIBT isteklerinin oldukça az sayıda $(\% 0,8)$ olduğu belirlenmiş olup, bu farklılığın etnik kökenli olabileceği düşünülmektedir.

Temporomandibular eklem ve çevre kemik yapıların morfolojik ve patolojik özellikleri, eklem boşluğu, KIBT'da bulunan multiplanar düzlemler ve üç boyutlu görüntüler sayesinde izlenebilmektedir. ${ }^{15,16}$ Çalışmamızda; TME patolojilerini değerlendirmek için istenen KIBT tetkikleri, tüm isteklerin \% 1,29'u olarak bulunmuştur. Warhekar ve ark. $^{8}$ tarafından yapılan araştırmada ise kurum içi istekler tüm isteklerin \% 12.4'ünü oluşturup, bu çalışma ile uyumsuz bir sonuç saptanmıştır. Bizim çalışmamızda bu sonucun düşük çıkması, yumuşak doku kontrastı en yüksek olan ve TME yapısı ve diskin değerlendirilmesinde en sık kullanılan görüntüleme yöntemi olan manyetik rezonans görüntülemenin daha çok tercih edilmesi ile açıklanabilir. ${ }^{17}$

Çalışmamızda Periodontoloji Anabilim Dalı tarafından yapılan KIBT incelemesi isteği tüm isteklerin \% 10,2'si iken, Warhekar ve ark. ${ }^{8}$ 'ının çalışmasında bu oran \% 6.1'dir. Araştırmamızda az bir farkla yüksek değer elde edilse de, benzer sonuçlar elde edilmiştir. Çalışmamızda Periodontoloji kliniği en çok implant planlaması için istek yapmıştır. Ayrıca bu bölüm, paranazal sinüs patolojilerinin değerlendirilmesi amacıyla da KIBT isteminde bulunmuştur.
Çocuk hastalarda KIBT isteklerinin; Ağız, Diş ve Çene Cerrahisi Anabilim Dalı başta olmak üzere sırasıyla Ortodonti, ADÇR, Endodonti ve Çocuk Diş Hekimliği Anabilim Dalları tarafından yapıldığı belirlendi. Fakültemizde çocuk hastaların diş çekimini de içeren cerrahi işlemleri Ağız, Diş ve Çene Cerrahisi bölümünde yapıldığından bu sonucun çıkması beklenebilir. Bu hastalarda KIBT çekimine karar verirken tanısal yarar göz önünde bulundurulmalı, uygun büyüklükte görüntüleme alanı kullanılarak, çocuğun yaşına ve vücut ağırlığına göre doz ayarlaması yapılmalıdır. ${ }^{18}$

İstek formları; KIBT çekim ihtiyacının doğruluğunun ve KIBT çekimi için gerekli görüntüleme alanının belirlenmesinde önemli rol oynar. Böylece hastaların gereksiz radyasyona maruz kalmaları önlenebilir. Bu nedenle istek formlarındaki tüm alanların hekimler tarafından doğru bir şekilde doldurulması ve hekimlerin buna gereken önemi göstermesi gerekmektedir.

\section{SONUÇ}

Her geçen gün kullanımı artan KIBT'ın istek nedenlerinin incelenmesi; kullanım alanlarının, sıklığının ve sınırılıklarının belirlenmesine katkı sağlayarak ilerleyen teknoloji ile üst düzey sistemlerin geliştirilmesine olanak tanıyabilir. Ayrıca ultrasonografi gibi iyonizan radyasyonun kullanılmadığı ileri görüntüleme tekniklerinin kullanımının yaygınlaşması ile de KIBT istek nedenlerinin yeni yapılacak çalışmalarla karşılaştırılması önerilebilir. 


\section{KAYNAKLAR}

1. Cotton TP, Geisler TM, Holden DT, Scwartz SA, Schindler WG. Endodontic applications of cone-beam volumetric tomography. J Endod 2007; 33: 1121-32.

2. Scarfe WC, Farman AG. What is cone-beam CT and how does it work? Dent Clin North Am 2008; 52: 70730.

3. Harorlı A, Akgül $M$, Yılmaz B, Bilge $O$, Dağistan $S$, Çakur B, et al. Ağız, diş ve çene radyolojisi. 1. baskı İstanbul; Nobel Tıp Kitapevleri Tic. Ltd Şti; 2014. p. 207-22.

4. Jaju PP, Jaju SP. Cone-beam computed tomography: Time to move from ALARA to ALADA. Imaging science in dentistry 2015; 45: 263-5.

5. SEDENTEXCT Guideline Development Panel. Radiation protection No 172. Cone beam ct for dental and maxillofacial radiology. Evidence based guidelines. Luxembourg: European Commission Directorate-General for Energy; 2012.

6. Horner K. Cone-beam computed tomography: time for an evidence based approach. Prim Dent J 2013; 2: 22 31.

7. Acar B, Kamburoğlu K. Use of computed cone beam tomography in periodontology. World J Radiol 2014; 6: 139-47.

8. Warhekar S, Nagarajappa S, Dasar PL, Warhekar AM, Parihar A, Phulambrikar T, et al. Incidental findings on cone beam computed tomography and reasons for referral by dental practitioners in indore city (m.p). J Clin Diagn Res 2015; 9: 21-4.

9. Ertaş ET, Kalabalık F. Bir Türk örneklem grubunda dental volümetrik tomografi endikasyonları. Atatürk Üniv. Diş Hek. Fak. Derg. J Dent Fac Atatürk Uni 2014; 24: 232-40.

10.Akarslan Z, Peker i. Bir diş hekimliği fakültesindeki konik ışınlı bilgisayarlı tomografi incelemesi istenme nedenleri. Acta Odontol Turc 2015; 32: 1-6.

11. White SC, Pharoah MJ. Oral Radiology: Principles and Interpretation: Elsevier Health Sciences 2014. p. 206.

12. Sirin Y, Guven K, Horasan S, Sencan S. Diagnostic accuracy of cone beam computed tomography and conventional multislice spiral tomography in sheep mandibular condyle fractures. Dentomaxillofac Radiol 2010; 39: 336-42.

13. Kaeppler G, Cornelius CP, Ehrenfeld M, Mast G. Diagnostic efficacy of cone-beam computed tomography for mandibular fractures. Oral Surg Oral Med Oral Pathol Oral Radiol 2013; 116: 98-104.

14. Mamta Raghav, Freny R. Karjodkar, Subodh Sontakke, Kaustubh Sansare. Prevalence of incidental maxillary sinus pathologies in dental patients on conebeam computed tomographic images. Contemp Clin Dent 2014; 5: 361-5.
15.Scarfe WC, Farman AG. Cone-beam computed tomography: White SC, Pharoah MJ. Oral Radiology: Principles and Interpretation. Mosby 2009. p. 225-43.

16.16. Lewis EL, Dolwick MF, Abramowicz S, Reeder SL. Contemporary imaging of the temporomandibular joint. Dent Clin North Am 2008; 52: 875-90.

17.17. Aksoy S, Orhan K. Temporomandibular eklem görüntüleme yöntemleri. Ondokuz Mayıs Üniversitesi Diş Hekimliği Fakültesi Dergisi 2010; 11: 69-78.

18.18. Madan K, Baliga S, Thosar N, Rathi N. Recent advances in dental radiography for pediatric patients: A review. J Med Radiol Pathol Surg 2015; 1: 21-5.

Yazışma Adresi:

Eda Didem YALÇIN

Gaziantep Üniversitesi

Diş Hekimliği Fakültesi

Ağız, Diş ve Çene Radyolojisi Anabilim Dalı

27410, Şehitkamil, Gaziantep

Tel : +905053148415

Faks : +903423610346

E-mail : didemyalcn@gmail.com 